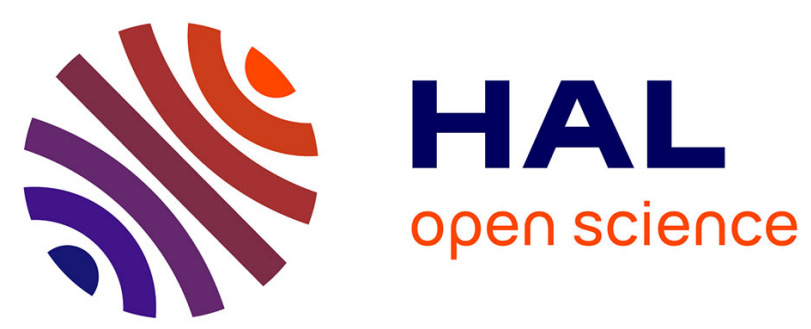

\title{
METALORGANIC CHEMICAL VAPOR DEPOSITION : EXAMPLES OF THE INFLUENCE OF PRECURSOR STRUCTURE ON FILM PROPERTIES
}

K. Jensen, A. Annapragada, K. Ho, J.-S. Huh, S. Patnaik, S. Salim

\section{- To cite this version:}

K. Jensen, A. Annapragada, K. Ho, J.-S. Huh, S. Patnaik, et al.. METALORGANIC CHEMICAL VAPOR DEPOSITION : EXAMPLES OF THE INFLUENCE OF PRECURSOR STRUCTURE ON FILM PROPERTIES. Journal de Physique IV Proceedings, 1991, 02 (C2), pp.C2-243-C2-252. 10.1051/jp4:1991230 . jpa-00249817

HAL Id: jpa-00249817 https://hal.science/jpa-00249817

Submitted on 1 Jan 1991

HAL is a multi-disciplinary open access archive for the deposit and dissemination of scientific research documents, whether they are published or not. The documents may come from teaching and research institutions in France or abroad, or from public or private research centers.
L'archive ouverte pluridisciplinaire HAL, est destinée au dépôt et à la diffusion de documents scientifiques de niveau recherche, publiés ou non, émanant des établissements d'enseignement et de recherche français ou étrangers, des laboratoires publics ou privés. 
METALORGANIC CHEMICAL VAPOR DEPOSITION : EXAMPLES OF THE INFLUENCE OF PRECURSOR STRUCTURE ON FILM PROPERTIES

\author{
K.F. JENSEN, A. ANNAPRAGADA, K.L. HO, J.-S. HUH, S. PATNAIK \\ and $S$. SALIM \\ Department of Chemical Engineering, Massachusetts Institute of \\ Technology, Cambridge, MA 02139, U.S.A
}

\begin{abstract}
The influence of precursor structure and reactivity on properties of compound semiconductors grown by metalorganic chemical vapor deposition (MOCVD) is discussed and illustrated with examples for growth of GaAs, $\mathrm{ZnSe}$, and $\mathrm{Al}_{\mathbf{x}} \mathrm{Ga}_{1-\mathrm{x}} \mathrm{N}$. Gas-phase and surface reactions of organometallic arsenic compounds provide understanding of variation in carbon incorporation levels with precursor structure. Surface spectroscopy studies reveal the critical role of hydrogen-arsenic bonds in reducing carbon levels. MOCVD of $\mathrm{ZnSe}$ with different organoselenium compounds demonstrate that the growth rate behaves as expected from the Seligand bond strengths, but also that unexpected minor pathways can make a precursor unsuitable by causing increased carbon incorporation. Interactions between organometallic precursors mean that the structure of the precursors cannot be manipulated independently for the individual precursors, but must be considered in terms of the overall growth chemistry. The use of a single-source precursor, versus separate precursors for MOCVD of compound semiconductors is discussed and illustrated with data for the growth of AlN and GaN.
\end{abstract}

\title{
1. - Introduction.
}

The technique of metalorganic chemical vapor (MOCVD) deposition has become widely used for growing $1 \mathrm{~nm}$ to $100 \mu \mathrm{m}$ thick films of insulators, semiconductors, and metals on a substrate of choice. /1/ The versatility of the technique derives from the wide range of organometallic compounds available as growth sources. The most extensive use of MOCVD has been in thin film growth of compound semiconductors, $/ 2 /$ which is often referred to as organometallic vapor phase epitaxy (OMVPE) to stress that single crystalline films are synthesized. The choice of organometallic precursors, as well as the MOCVD reactor configuration and operation, determine whether or not a particular compound semiconductor can be grown with controlled optical and electronic properties.

The reactor parameters affect the transport phenomena that govern the degree of desired and unwanted parasitic gas-phase reactions as well as the access of precursors to the growth interface. The primary effect is on film thickness and composition uniformity, but a poor design or choice of deposition conditions can also lead to extensive parasitic gas-phase reactions resulting in impurity incorporation or, in the worst case, no film growth. These issues have been addressed extensively elsewhere. /2/3/ Here we make use of examples to illustrate how the structure of organometallic precursors influence the materials properties of the deposited film. 
Three examples are chosen to demonstrate various aspects of the chemical reactions underlying the MOCVD process. The first example concerns the role of hydrogen bound to arsenic in the growth of GaAs by conventional MOCVD and the related growth process of atomic layer epitaxy (ALE). The second example shows the effect that changing the structure of the organometallic Se has on MOCVD grown ZnSe. It also addresses chemical approaches for reducing the interactions between $\mathrm{Se}$ and $\mathrm{Zn}$ precursors. The last example considers the use of a single-source precursor already containing the III-V bond as opposed to using separate group III and V precursors. Key results are summarized below for each of the three examples. Details of the described studies are given in the literature cited and in forthcoming publications.

\section{2.- Surface Reactions of Organometallic Arsenic and Gallium Precursors.}

Understanding the growth chemistry of organometallic compounds of gallium and arsenic is of importance in understanding routes to carbon incorporation in conventional MOCVD, as well as in the related growth processes of ALE and metalorganic molecular beam epitaxy (MOMBE). Replacement of trimethygallium (TMG) by triethylgallium (TEG) in MOCVD of GaAs with $\mathrm{AsH}_{3}$ reduces carbon incorporation. /4/ This difference in carbon incorporation when using TMG and TEG is pronounced in MOMBE where TMG leads to heavily carbon contaminated films with hole concentrations above $10^{18} \mathrm{~cm}^{-3}$, while carrier concentrations below $10^{15} \mathrm{~cm}^{-3}$ can be achieved with TEG. $/ 5 /$ ALE has been achieved with TMG, but not with TEG, and ALE grown films show higher levels of carbon than those grown by MOCVD. /6/

Development of organometallic As sources has primarily been driven by the desire to replace $\mathrm{AsH}_{3}$ with less toxic, low vapor pressure liquid precursors. /2,7,8/ The number of alkyl-ligands substituted in place of hydrogen on the As are critical to obtaining good electrical properties. Hydrogen directly attached to As is believed to be responsible for removing radicals from the surface before they can decompose and lead to incorporation of carbon into the film. $/ 7,8 /$

The reactions of trimethylgallium TMG and TEG on GaAs have been investigated by a range of surface science techniques, including molecular beam scattering, temperature programmed desorption, and $x$-ray photoelectron spectroscopy (XPS). 19-12/ It is generally recognized that TMG chemisorbs dissociatively and that methyl radicals and TMG fragments desorb upon heating of the GaAs substrate. TEG also appears to adsorb dissociatively, but the process is more complex than it is for TMG. Few studies have been conducted on the surface chemistry of arsenic precursors. Tertiarybutylarsine ( $t$-BAs) is of particular interest since it has emerged as one of the main organometallic As-sources for the replacement of $\mathrm{AsH}_{3}$, yielding electrical properties comparable to those obtained with arsine. /13/

In order to gain new insight into the surface reactions of adsorbed methyl and ethyl groups, as well as the role of surface As-H moieties, we present Fourier transform infrared (FTIR) spectroscopy investigations of the surface reactions of TMG, TEG, and $t$-BAs GaAs(100) surfaces. Infrared (IR) spectroscopy is a natural choice for studying the surface chemistry of organometallic compounds since adsorbed alkyl groups and surface hydrides have very distinct signatures in the IR spectrum. The experimental set-up used in this study has been described elsewhere. /14/ Briefly, it consists of a load-locked UHV chamber with the capability to perform infrared multiple internal reflection (IR-MIR) experiments while dosing the sample. A mass spectrometer allows detection of desorbing species. 
The experimental observations suggest the reaction mechanism shown schematically in Figure 1. /15/ TMG primarily chemisorbs dissociatively and the majority of the resultant reaction products, methyl radicals and either mono- or dimethylgallium, desorb. This behavior is consistent with previous observations of the surface reactions of TMG. 19-11/ On the $c(2 \times 8)$ As-rich GaAs(100) surface a small fraction of methyl groups is dehydrogenated to bridging and terminal $\mathrm{CH}_{2}$ species corresponding to a surface coverage of $\sim 0.2 \%$ of a monolayer. The dehydrogenation of the methyl radicals results in the formation of $\mathrm{AsH}$ and $\mathrm{AsH}_{2}$ species on the surface. The terminal $\mathrm{CH}_{2}$ species are stable on the surface to temperatures as high as $550-600^{\circ} \mathrm{C}$. Because the direct desorption of $\mathrm{CH}_{2}$ would involve the simultaneous breaking of two surface bonds, the removal of this species from the surface most likely has to proceed through hydrogenation to methyl groups, which then desorb. Further dehydrogenation of $\mathrm{CH}_{2}$ species represents a possible route to carbon incorporation which is consistent with the selective incorporation of carbon onto the arsenic sublattice during MOCVD of GaAs. This carbon incorporation mechanism could also explain the larger amount of carbon typically incorporated during ALE than in MOCVD. Under typical MOCVD conditions, $\mathrm{AsH}_{3}$ is present in large amounts providing surface hydrogen for the hydrogenation of any $\mathrm{CH}_{2}$ species formed, whereas $\mathrm{AsH}_{3}$ is absent during the TMG treatment step in ALE, thereby allowing a larger surface coverage of $\mathrm{CH}_{2}$ species.

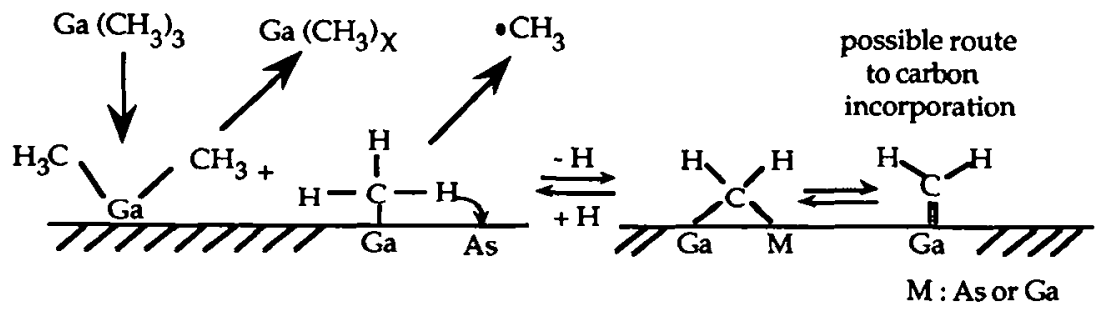

Figure 1. Proposed mechanism for TMG decomposition consistent with IR data.

TEG is shown to adsorb dissociatively resulting in the generation of ethyl and ethylene species. The adsorption process also leads to the formation of adsorbed hydrogen, supposedly through a surface $\beta$-hydrogen elimination reaction. The presence of the hydrogen is consistent with the reduction in carbon incorporation observed in MOCVD /4/and MOMBE /5/ when replacing TMG with TEG.

t-BAs is shown to decompose primarily by homolysis to form a tertiary butyl group and $\mathrm{AsH}_{2}$. 14/ Significant infrared absorption from surface hydrocarbons is only observed for Ga-rich $\mathrm{GaAs}(100)$ surfaces (cf. Figure 2) where the tertiarybutyl radical appears to undergo dehydrogenation to an unsaturated species which is stable on the surface. The concentration of surface hydrogen resulting from $t$-BAs adsorption is estimated from the areas under the As- $\mathrm{H}$ peaks in the IR spectra /15/ and is plotted as a function of surface temperature in Figure 3 . The data agrees well with the desorption temperature of hydrogen from $\mathrm{GaAs}(100)(\sim 500 \mathrm{~K}) / 12 \%$. Above this temperature, the surface concentration is controlled by the decomposition rate of $t$-BAs, and therefore increases with increasing temperature. Below $\sim 500 \mathrm{~K}$, the desorption rate is very low, which results in the accumulation of hydrogen on the surface. The data clearly shows that the decomposition of $t$-BAs is sufficient to maintain surface As-H species even at temperatures significantly above the hydrogen desorption temperature. The As- $\mathrm{H}$ species presumably play a key role in the hydrogenation of $\mathrm{CH}_{2}$ species and the corresponding reduction in carbon levels. 


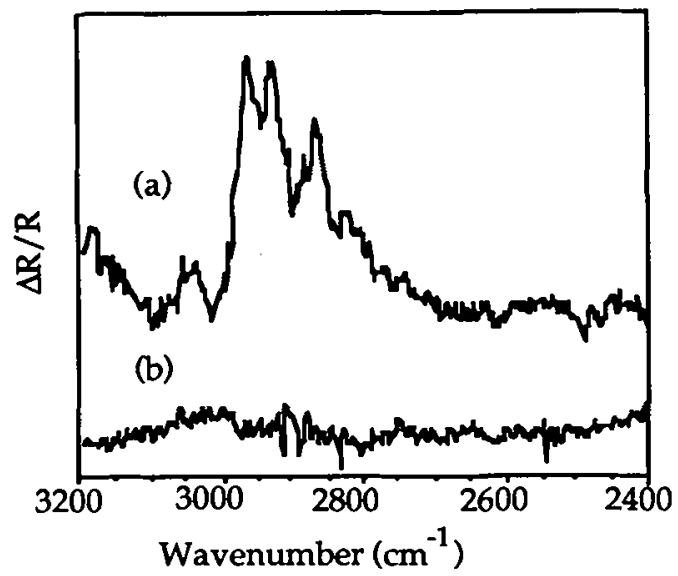

Figure 2. Infrared spectra of $t$-BAs on GaAs(100) (a) Ga-rich and (b) As-rich.

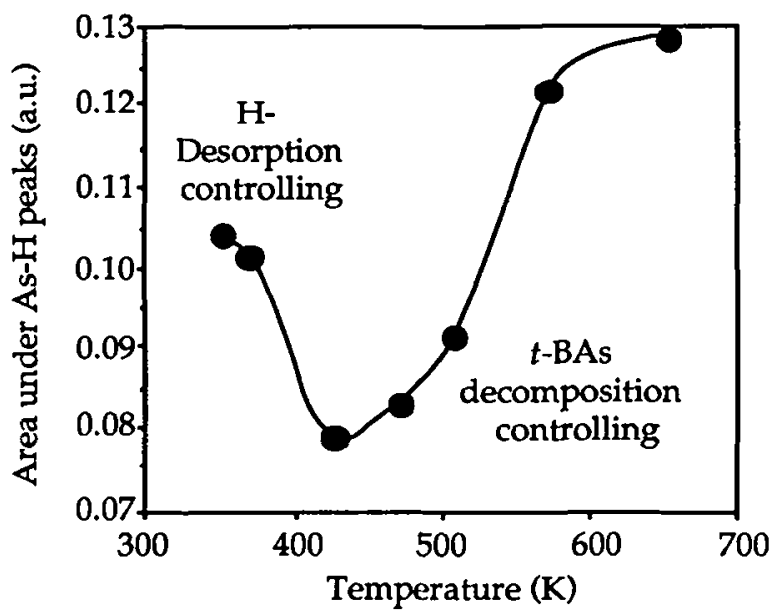

Figure 3. Change in amount of surface hydrogen as a function of temperature during surface decomposition of $t$-BAs.

\section{3.- MOCVD of ZnSe: The Choice of Precursors.}

High quality epitaxial layers of $\mathrm{ZnSe}$ that can be doped controllably have a well-recognized potential use in both photonic and electronic applications, either as blue light emitters or as insulating layers, e.g., in MIS devices. Good quality ZnSe with high electron mobility and a large ratio of free exciton emission to bound exciton emission, has been obtained with the source combination $\mathrm{H}_{2} \mathrm{Se}$ and dimethylzinc $(\mathrm{DMZn})$ ) /16/ However, the poor morphology of the films resulting from parasitic reactions has led to the investigation of alternate Se and $\mathrm{Zn}$ precursors that would be less likely to participate in parasitic reactions. /17-20/

Organometallic Se sources of the form R-Se-R', specifically diethylselenide (DESe), methylallylselenide (MASe), and diallylselenide (DASe), have been used in reduced 
pressure MOCVD of ZnSe with dimethylzinc (DMZn) as the $\mathrm{Zn}$ source. The film properties are shown to depend strongly on the structure and reactivity of the Se compound. Figure 4 shows that the effect of growth temperature on deposition rates is similar for the different organometallic Se sources; a thermally activated growth regime at lower temperatures indicative of kinetic control, followed by a plateau regime corresponding to mass transfer control. The observed trends in growth rates and decomposition temperatures correlate with the stability of the ligands on the precursor species, i.e., the temperature necessary to achieve a particular growth rate decreases when going from diethyl to methylallyl and diallyl. This trend is also confirmed by mass spectrometric pyrolysis studies.

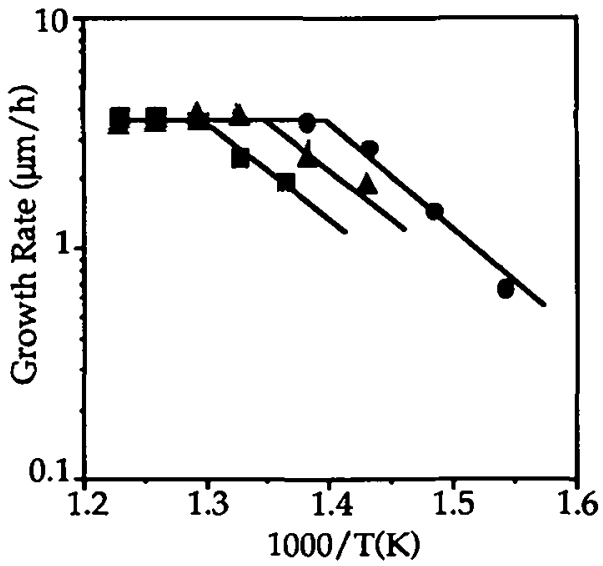

Figure 4. Growth rate of $\mathrm{ZnSe}$ as a function of reciprocal growth temperature (K) for different selenium precursors with VI/II = 2. (O) DASe, (A) MASe and ( $(1)$ DESe.

The use of diethylselenide (DESe) produces films with good surface morphology and photoluminescence characteristics, but at relatively high growth temperatures, $450-500^{\circ} \mathrm{C}$ $/ 17,18 /$. The higher stability of the allyl radical, compared to the methyl and ethyl radicals, makes allyl-based organometallic compounds thermally less stable, as also demonstrated for the analogous Te compounds for MOVPE of CdTe. /21/ As a consequence, organometallic Se sources involving allyl ligands have a lower growth temperature for ZnSe, but methylallylselenide (MASe) leads to extensive carbon incorporation. /19/ We explore whether this is an inherent problem in the use of allyl sources or whether it is connected to the methyl group in MASe by using two different allyl-Se compounds, MASe and diallyl selenide (DASe), with dimethylzinc (DMZn) as the common $\mathrm{Zn}$ source. /20/ The ZnSe layers are compared in terms of surface morphology, growth rate, electrical properties and carbon incorporation, with material grown from diethyl selenide (DESe) and from $\mathrm{H}_{2} \mathrm{Se}$. The results are analyzed in terms of the pyrolysis chemistry of the allyl based organometallic Se compounds. Films grown with both DASe and MASe have high levels of carbon contamination indicating that the carbon incorporation is related to the allyl ligand and not the methyl group in MASe. Se source decomposition studies suggest that the pyrolysis mechanism for the allyl selenides not only involves homolysis, but also an intra-molecular rearrangement leading to a moiety with a $\mathrm{C}=\mathrm{Se}$ bond. This interpretation is consistent with known mechanisms for pyrolysis of allyl sulfides and ethers.

The Se precursor studies suggest that $\mathrm{H}_{2} \mathrm{Se}$ would be the preferred Se source and alternative $\mathrm{Zn}$ compounds should be explored to avoid prereaction problems. Growth results with $\mathrm{H}_{2} \mathrm{Se}$ and the adduct compound, dimethylzinc-triethylamine, indicate that pre-reaction is eliminated and ZnSe films with improved morphology are deposited at temperatures 
around $300-350^{\circ} \mathrm{C}$ analogous to results reported by Wright et al../22/ Figures 5 (a) and (b) compare growth rates obtained with the standard DMZ source and the adduct for varying pressure and temperature, respectively. The growth rate shows the same behavior, within experimental accuracy, at high temperatures and pressures indicating that the ethylamine has no effect under those conditions. The decreasing growth rate with increasing temperatures is in stark contrast to the usual growth rate variation with temperature, as displayed in Figure 4, and demonstrates the severity of the parasitic reactions retarding the growth of $\mathrm{ZnSe}$ from $\mathrm{DMZn}$ and $\mathrm{H}_{2} \mathrm{Se}$. The presence of ethylamine increases the growth rate at low temperatures and low pressures, but the mechanism is not understood. Infrared spectroscopy studies suggest that the adduct is decomposed at typical growth conditions. /23/ Addition of pyridine, which has analogous donor properties as ethylamine, produces effects similar to those reported for the adduct source. /24/ Thus, it is unlikely that the blocking of is caused by a simple Lewis acid-base adduct in the gas-phase. The strong effect of the ethylamine at low pressures, at which point gas-phase reactions are reduced in importance, indicates that surface reactions also play a significant role in the growth of $\mathrm{ZnSe}$ from $\mathrm{H}_{2}$ Se and DMZn:N(Et) 3 .
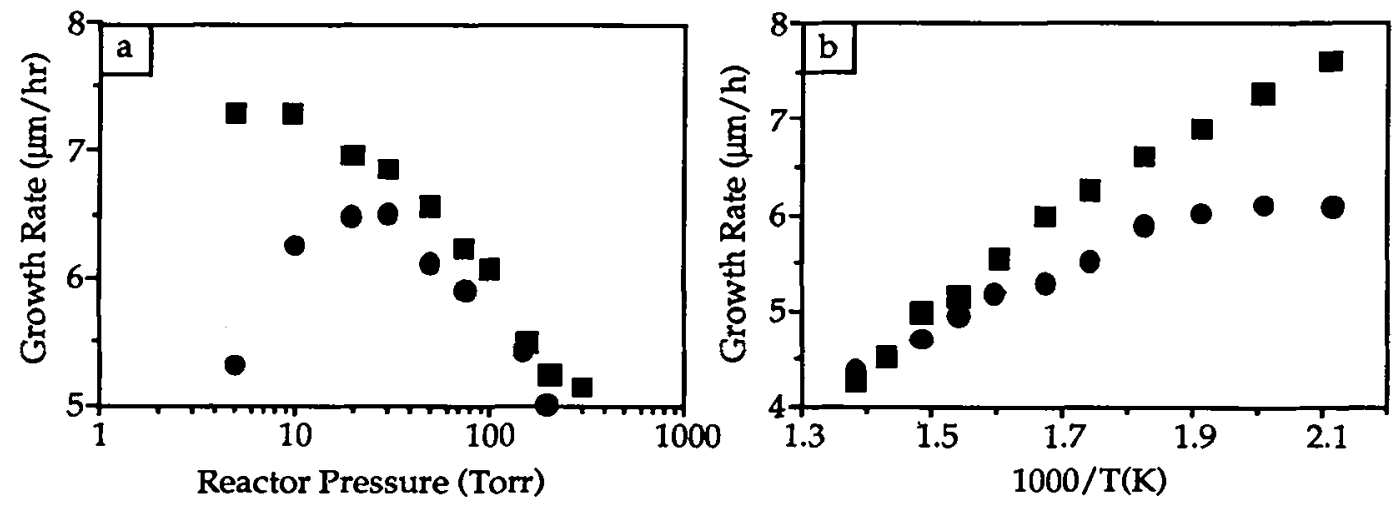

Figure 5. Growth rates of ZnSe when using $\mathrm{H}_{2}$ Se with DMZn (O) and DMZn:N(Et) $3(\square)$ for varying reactor pressure (A) and varying deposition temperature (B).

Deposition temperature for $a=250^{\circ} \mathrm{C}$, reactor pressure for $\mathrm{b}=30$ Torr.

\section{4.- Deposition of AlN and GaN by using single-source precursors.}

$\mathrm{Al}_{\mathbf{x}} \mathrm{Ga}_{1-\mathrm{x}} \mathrm{N}$ is a wide bandgap semiconductor with promising applications for optoelectronic devices operating in the ultraviolet-blue spectral region, but device applications have not been fully achieved because of the difficulty of incorporating nitrogen into the films at the high substrate temperatures $\left(\sim 900^{\circ} \mathrm{C}\right)$ used in conventional MOCVD processes. Despite the high $\mathrm{V} / \mathrm{III}$ ratios $(>2,000)$ typically employed, undoped $\mathrm{Al}_{\mathbf{x}} \mathrm{Ga}_{1-\mathrm{x}} \mathrm{N}$ films are degenerate $\mathrm{n}-$ type, attributed to native nitrogen defects. The use of single-source precursors, already containing the metal-nitrogen bond and designed to decompose at low temperatures, has been suggested as a means for circumventing this problem. Interrante et al. /25/ pioneered the use of dimethylaluminumamide $\left[\left(\mathrm{CH}_{3}\right)_{2} \mathrm{AlNH}_{2}\right]_{3}$ while Gladfelter et al. /26/ considered a number of Al-N-organometallic compounds, of which diethylaluminumazide $\left[\mathrm{Et}_{2} \mathrm{AlN}_{3}\right]_{3}$ (DEAA) deposited the highest purity thin films of AlN. Kouvetakis and Beach /27/ demonstrated that the analogous gallium compound, diethylgalliumazide $\left[\mathrm{Et}_{2} \mathrm{GaN}_{3}\right]_{3}$ (DEGA), produced amorphous GaN films. Here we compare the growth performance of the azide sources with that achieved in conventional MOCVD growth with separate 
nitrogen and metal sources, specifically triethylgallium (TEAl), triethylgallium (TEG), and $\mathrm{NH}_{3}$.

The growth mechanism proposed for MOCVD of AlN from DEAA, as illustrated in Figure 6 , involves the adsorption of DEAA and elimination of $\mathrm{N}_{2}$ from the azide functionality, followed by the liberation of ethylene via a $\beta$-hydride elimination reaction. $/ 26,28 /$ The remaining intermediate can subsequently undergo a final rearrangement to liberate ethane, or another $\beta$-hydride reaction. This mechanism is supported by the product distribution observed in the temperature programmed reaction experiments and in infrared spectra of $\mathrm{AlH}$ and $\mathrm{AlH}_{2}$ moieties in films grown at temperature below $750^{\circ} \mathrm{C}$ as shown in Figure 7. $/ 28 /$. The strong absorbance peak at $\sim 673 \mathrm{~cm}^{-1}$ in all samples corresponds to the transverse optical mode of AlN. The symmetric and asymmetric $\mathrm{AlH}_{\mathbf{x}}$ stretching frequencies at 2140 $\mathrm{cm}^{-1}$ and $2088 \mathrm{~cm}^{-1}$ decrease gradually with increasing growth temperatures due to the desorption of hydrogen from the $\mathrm{AlH}_{\mathbf{x}} \mathrm{N}$ intermediate. In comparison, there is no significant hydrogen incorporation into AlN films grown from the conventional precursors (TEAl and $\mathrm{NH}_{3}$ ). Although it is possible to deposit high-purity AlN films from DEAA at relatively low temperatures, separate precursors appear to produce AlN films with better crystalline properties. This may be due to either the presence of impurities in the DEAA precursor or the reduced surface mobility of the Al-N species relative to the individual $\mathrm{Al}$ and $\mathrm{N}$ surface species.

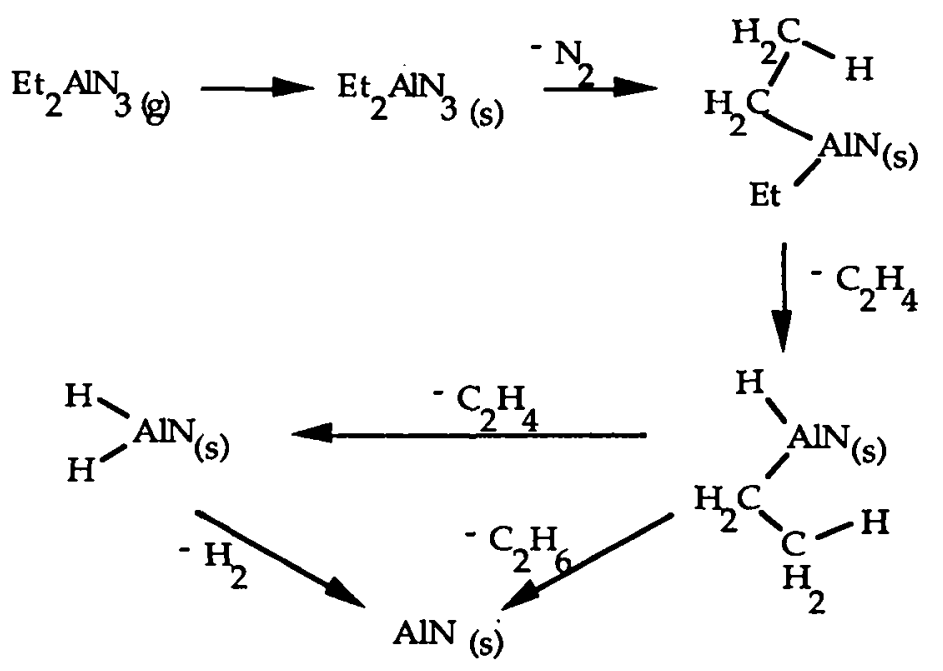

Figure 6. Proposed mechanism for the growth of AlN from DEAA /26/

DEGA has been reported to deposit thin films of amorphous GaN at low temperatures $\left(>275^{\circ} \mathrm{C}\right) / 27 /$, but it is not possible to grow crystalline GaN from DEGA alone. The growth rate diminishes drastically at temperatures above $400^{\circ} \mathrm{C}$ due to gas-phase depletion of the precursor $/ 29 /$. By introducing $\mathrm{NH}_{3}$, it is possible to grow $\mathrm{GaN}$ films from DEGA at higher temperatures $\left(>500^{\circ} \mathrm{C}\right)$ with better crystalline and optical properties than with both the single-source and separate nitrogen and gallium sources. $/ 30 /$ Figure 8 shows $x$-ray diffraction (XRD) data for three GaN films grown on (0001)-oriented sapphire substrates from DEGA and $\mathrm{NH}_{3}$ at (a) 600 , (b) 650 , and (c) $700{ }^{\circ} \mathrm{C}$, respectively. The film thicknesses range from 4 to $8 \mu \mathrm{m}$. For comparison, the XRD profile of a GaN film grown from TEG and $\mathrm{NH}_{3}$ at $750^{\circ} \mathrm{C}$ is also shown on the same graph (curve (d)). All films grown from DEGA 


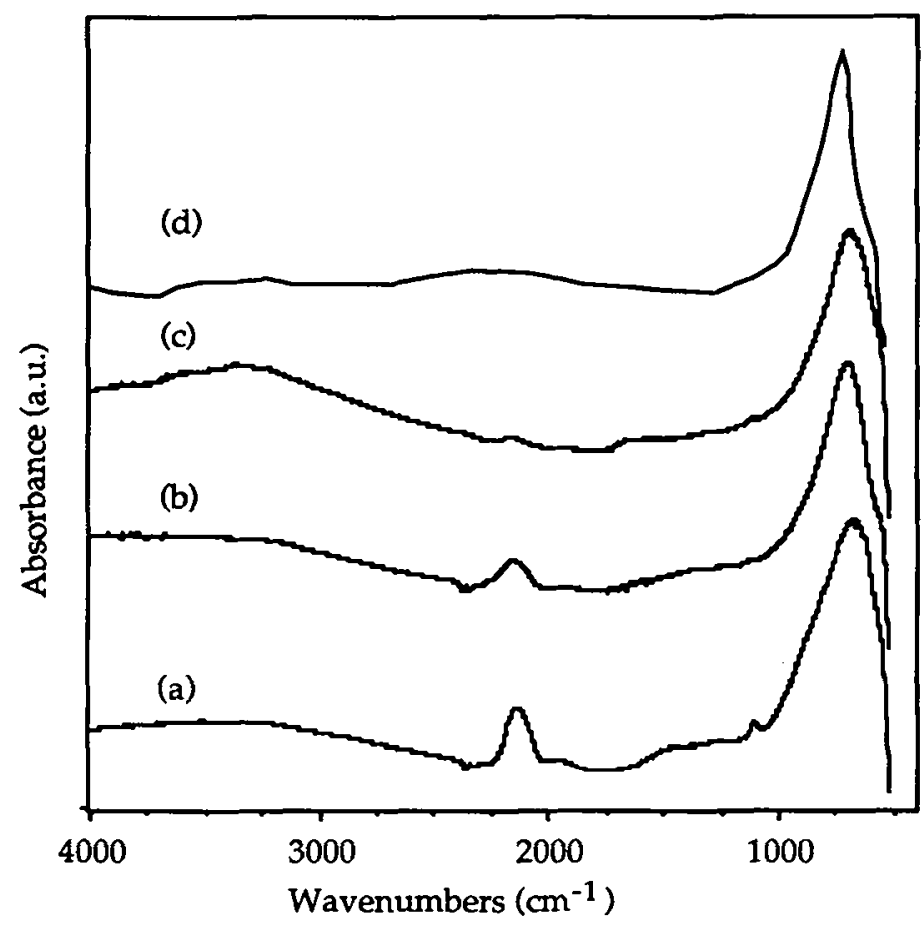

Figure 7. Infrared spectra of AlN grown with DEAA at $450^{\circ} \mathrm{C}(\mathrm{a}), 750^{\circ} \mathrm{C}(\mathrm{b}), 870^{\circ} \mathrm{C}$, and with TEAl and $\mathrm{NH}_{3}$ at $800^{\circ} \mathrm{C}$ (d).

and $\mathrm{NH}_{3}$ are highly oriented. The increase of (0002) $\mathrm{GaN}$ peak intensity from $600-700^{\circ} \mathrm{C}$ corresponds to grain growth and increase in structural order. All films grown on $\mathrm{Si}$ substrates under identical conditions are polycrystalline. Curve (d) reveals the presence of (1000) and (1101)-oriented grains in the film grown from conventional sources, an indication of structural imperfections. The bandgap of the $\mathrm{GaN}$ films grown at $700^{\circ} \mathrm{C}$ and $750^{\circ} \mathrm{C}$ are determined from UV-vis absorption spectra to be 3.3-3.4 eV, in good agreement with literature data. The films are n-type semiconductors with typical electron mobilities of $50 \mathrm{~cm}^{2} / \mathrm{V}-\mathrm{s}$ and carrier concentrations around $2 \times 10^{18} \mathrm{~cm}^{-3}$. These values are better than those of GaN films grown from conventional sources at $700^{\circ} \mathrm{C}$. Even though $\mathrm{NH}_{3}$ still has to be added to grow good quality $\mathrm{GaN}$, the V/III ratio is much smaller than for conventional MOCVD; $\sim 10$ versus $\sim 1000$. The underlying mechanism is not understood at this point. It is possible that $\mathrm{NH}_{3}$ acts as a donor blocking the formation of DEGA trimers and the subsequent gas-phase polymerization reactions that otherwise deplete DEGA.

\section{5.- Conclusions.}

By way of three examples we have illustrated the pronounced effect that the precursor structure has on film properties synthesized by MOCVD. For MOCVD of GaAs surfaces, infrared spectroscopy has confirmed the critical role of As- $\mathrm{H}$ in reducing carbon incorporation, as conjectured from growth experiments. The spectroscopy data further 
suggest a mechanism for carbon incorporation from methyl groups via methylene surface species that is consistent with observed growth trends.

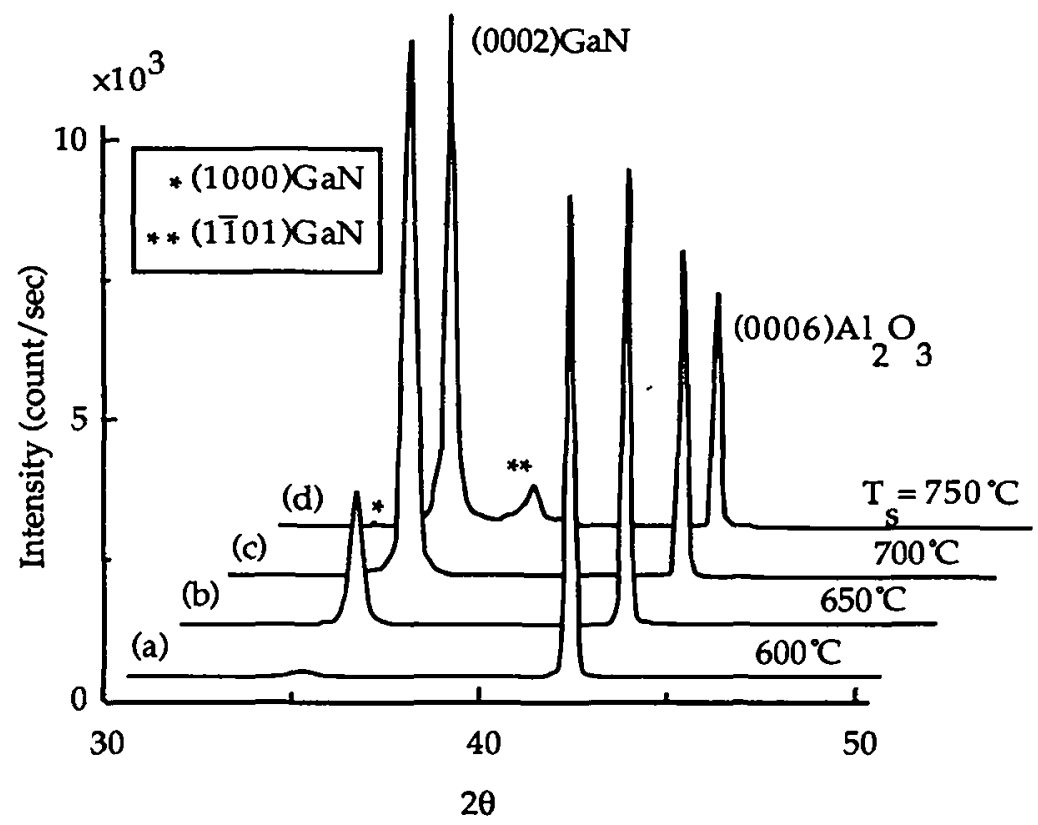

Figure 8. X-ray diffraction profiles of GaN grown on (0001)-oriented sapphire substrates from DEGA and $\mathrm{NH}_{3}\left((\mathrm{a}),(\mathrm{b})\right.$ and (c)), and TEG and $\mathrm{NH}_{3}((\mathrm{~d}))$.

Data for growth of ZnSe with organometallic Se sources demonstrate the well-known reduction in growth temperature with the increasing stability of the radical formed by homolysis. However, the high levels of carbon incorporation attributed to a minor, intramolecular rearrangement reaction also illustrate the limitations of such "rules-of-thumb" and the importance of understanding the complete reaction mechanism. The use of the adduct source $\mathrm{DMZn}: \mathrm{N}(\mathrm{Et})_{3}$ to minimize prereaction problems plaguing the growth of ZnSe with $\mathrm{H}_{2} \mathrm{Se}$ and DMZn indicates that, besides changing the precursor structure, it may be possible to modify the deposition process by adding a"blocking" agent for unwanted reactions provided that the added species does not lead to increased impurity incorporation.

The use of a single-source precursor, as in the deposition of AIN from DEAA, appears to be an attractive means for reducing the decomposition temperature, but the generally poorer crystal quality as compared to films prepared with separate sources, raises issues related to surface mobilities of AIN moieties, as opposed to individual $\mathrm{N}$ and $\mathrm{Al}$ species. Finally, the growth of $\mathrm{GaN}$ with DEGA and $\mathrm{NH}_{3}$ shows that the performance of a single-source precursors may be enhanced by adding a small amount of $\mathrm{NH}_{3}$ purportedly blocking parasitic reactions and contributing to maintaining an excess of the most volatile film constituent (N).

Many more examples of the critical impact of the precursor's chemical structure on MOCVD grown films could be cited, including selective growth and atomic layer growth. Gas-phase and surface reaction studies of the underlying chemical pathways, combined with careful materials characterization, will be essential to develop the fundamental 
understanding needed to go beyond trial-and-error and rules-of-thumb approaches to designing and selecting precursor for the multitude of MOCVD applications.

\section{6.- References}

11/ Jensen, K.F., Kern, W., in Thin Film Processes-II, Vossen, J. and Kern, W. (Eds.), Academic Press, San Diego (1991) p. 283.

12/ Kuech, T.F. and Jensen, K.F., in Thin Film Processes-II, Vossen, J. and Kern, W. (Eds.), Academic Press, San Diego (1991) p. 369

13/ Jensen, K.F., Einset, E.O., and Fotiadis, D.I., Annual Reviews of Fluid Mechanics, 23 (1991) 199.

/4/ Kuech, T.F. and Potemski, R. , Appl. Phys. Lett., 47, (1985) 821.

15/ Pütz, N., Heinecke, H., Weyers, M., Heyen, M., Lütz, H., and Balk, P., J. Crystal Growth, 74 (1986) 292.

16/ Tischler, M.A. and Bedair, S.M., in Atomic Layer Epitaxy, Suntola, T. and Simpson, M. , (Eds.), Chapman and Hall, New York (1990) p. 110.

77/ Brauers, A., J. Crystal Growth, 107 (1991) 281.

18/ Lum, R.M., Klingert, J.K., and Lamont, M.G., J. Crystal Growth, 89 (1988) 137.

19/ Yu, M., Memmert, U., Buchan, N.I., and Kuech, T.F., Mat.Res.Soc. Symp.Proc., 204 (1991) 37.

/10/ Donnelly, V.M., and MacCaulley, J.A., Surf Sci., 238 (1990) 34.

/11/ Creighton, J.R., Surf Sci., 234 (1990) 287.

112/ Murrell, A.J., Wee, A.T.S., Fairbother, D.H., Singh, N.K., Foord, J.S., Davies, G.J., and Andrews, D.A., J. Appl. Phys., 68 (1990) 4053.

/13/ Haacke, G., Watkins, S.P., and Burkhard, H., Appl. Phys. Lett., 54 (1989) 2029.

/14/ Annapragada, A.V., and Jensen, K.F., Mat.Res.Soc. Symp.Proc., 204 (1991) 53.

/15/ Annapragada, A.V., and Jensen, K.F., Mat.Res.Soc. Symp.Proc., in press

/16/ Giapis, K. P. , Lu, D. C., and Jensen, K. F., Appl. Phys. Lett., 54 (1989) 353.

/17/ Giapis, K. P. , and Jensen, K. F., J.Crystal Growth, 101 (1990) 111.

/18/ Giapis, K. P. , Lu, D. C., Fotiadis, D.I., and Jensen, K. F., J.Crystal Growth, 104 (1990) 629.

/19/ Giapis, K. P. , Jensen, K. F., Potts, J. E., and Pachuta, S. J., J. Electron. Mater. 19 (1990) 453.

/20/ Patnaik, S., Jensen, K. F., and Giapis, K. P , J.Crystal Growth, 107 (1991) 390.

/21/ Hoke, W. E., Lemonias, P. J., and Korenstein, R., J. Mater. Res., 3 (1988) 329.

122/ Wright, P.J., Parbrook, Cockayne, B., Jones, A.C., Orell, E.D., O'Donnell, K.P., and Henderson, B., J.Crystal Growth, 94 (1989) 441.

123/ Khan, O.F.Z., O'Brien, P., Hamiliton, P.A., Walsh, J.R., and Jones, A.C., Chemtronics, 4 (1989) 244.

/24/ Wright, Cockayne, B., Oliver, P.E., and Jones, A.C., J.Crystal Growth, 108 (1991) 525.

/25/ Interrante, L.V., Lee, W., McConnell, M., Lewis, N., and Hall, E., J. Electrochem. Soc., 136 (1989) 472.

/26/ Gladfelter, W.L.,Boyd, D.C. , Hwang, J-W., Hassch, R.T.,Evans, J.F., Ho, K-L., and Jensen, K.F., Mat. Res. Soc. Symp. Proc., 131 (1989) 447.

/2/ Kouvetakis, J, and D.B. Beach,D.B., Chem. Materials, 1 (1989) 476.

/28/ Ho, K-.L, Annapragada, A.V., Jensen, K.F., Hanson, S.A., Gladfelter, W.L., and Evans, J.F., Proc. Eleventh Int. Conf. CVD, (K.E. Spear and G.W. Cullen, Eds), Electrochem. Soc., Pennington, NJ, (1990) p. 388.

/29/ Ho, K-L, Jensen, K.F., Hwang, J.-W., Gladfelter,W.L., and Evans, J.F., J. Crystal Growth, 107 (1991) 376.

/30/ Ho, K-L, Jensen, K.F., Hwang, J.-W., Evans, J.F., and Gladfelter,W.L., Mat. Res. Soc. Symp. Proc., 204 (1991) 101. 